\title{
Screening of Women in the Antenatal Period for Thalassemia Carrier Status: Comparison of NESTROFT, Red Cell Indices, and HPLC Analysis
}

\author{
Suman Lata Mendiratta ${ }^{1}$ Surbhi Bajaj ${ }^{1}$. \\ Sangeeta Popli $^{1} \cdot$ Sompal Singh $^{2}$
}

Received: 3 March 2015/Accepted: 27 April 2015/Published online: 29 May 2015

(C) Society of Fetal Medicine 2015

\begin{abstract}
Thalassemia is the most common inherited blood disorder in India. In $\beta$-thalassemia, there is defective formation of $\beta$-globin chains which leads to severe anemia requiring repeated blood transfusions. With the help of antenatal screening for $\beta$-thalassemia followed by prenatal diagnosis, "couples at-risk" can avoid having affected children without remaining childless and can spare themselves from months of anxiety awaiting the outcome of pregnancy $[1,2]$. The present study was conducted from 2008 through 2010. One thousand antenatal women with gestational age less than 20 weeks were studied. NESTROFT, CBC, and HPLC analysis of blood samples were done in all the patients. Husbands of women detected to be carriers of $\beta$-thalassemia were also screened to identify the "high-risk couples". Counseling and prenatal diagnosis was offered to the couple, where both husband and wife were positive for thalassemia trait. Of 1000 women studied during antenatal period, $79(7.9 \%)$ were detected to have thalassemia trait. Husbands of these women were counseled and advised HPLC test. Only two husbands were diagnosed to have $\beta$-thalassemia trait. Of these two "at-risk couples", genetic testing in one woman showed the fetus to be a carrier, and this pregnancy was continued. In the other lady, the fetus was diagnosed to have thalassemia major
\end{abstract}

Suman Lata Mendiratta

sumanmendi@yahoo.co.in

1 Obstetrics \& Gynaecology Department, North DMC Medical College \& Hindu Rao Hospital, Malka Ganj, New Delhi 110007, India

2 Pathology Department, North DMC Medical College \& Hindu Rao Hospital, Malka Ganj, Delhi, India and she chose to terminate the pregnancy. The sensitivity and specificity of NESTROFT was found to be $78.48 \%$ and $94.14 \%$, respectively. These were much better than those of $\mathrm{RBC}$ count $\left(>5 \mathrm{million} / \mathrm{mL}^{3}\right), \mathrm{MCV}(<80 \mathrm{fL})$ or $\mathrm{MCH}(<27 \mathrm{pg})$. The positive predictive value and negative predictive value of NESTROFT was found to be $53.45 \%$ and $98.08 \%$, respectively. These were also more than those of RBC count $\left(>5 \mathrm{million} / \mathrm{mL}^{3}, \mathrm{MCV}\right.$ ( $<80 \mathrm{fL}$ ), or MCH $(<27 \mathrm{pg})$. HPLC analysis of the blood is the gold standard for diagnosis of thalassemia trait, but due to its high cost, sophisticated and expensive equipment, it cannot be used in large screening programs. Screening by hematological parameters requires automated analyzer which again may not be possible in small setups catering to a large number of pregnant women. NESTROFT proved to be sensitive, cost effective, rapid, and can be used for field studies and mass-screening programs.

Keywords $\beta$-thalassemia trait - Antenatal screening . Prenatal diagnosis · HPLC

$\begin{array}{ll}\text { Abbreviations } & \\ \text { BTT } & \beta \text {-thalassemia trait } \\ \text { CBC } & \text { Complete blood count } \\ \text { CVS } & \text { Chorionic villus sampling } \\ \text { Hb } & \text { Hemoglobin } \\ \text { HPLC } & \text { High-performance liquid chromatography } \\ \text { LSCS } & \text { Lower (uterine) segment cesarean section } \\ \text { MCH } & \text { Mean corpuscular hemoglobin } \\ \text { MCHC } & \text { Mean corpuscular hemoglobin concentration } \\ \text { MCV } & \text { Mean corpuscular volume } \\ \text { NESTROFT } & \text { Naked eye single tube red cell osmotic } \\ & \text { fragility test } \\ \text { PCV } & \text { Packed cell volume } \\ \text { RBC } & \text { Red blood cell }\end{array}$




\section{Introduction}

Thalassemia is the most common inherited blood disorder in India. It is characterized by a defective formation of hemoglobin chains which leads to severe anemia requiring repeated blood transfusions. According to World Health Organization (WHO), $4.5 \%$ of world's population is affected by thalassemia and allied disorders. A study by Indian Council of Medical Research (ICMR) showed that $5.5 \%$ of school children in Delhi were $\beta$-thalassemia carriers. In some areas, the frequency of carriers of $\beta$ thalassemia is even higher $(8 \%-10 \%)$.

Every year, about 8000 babies with thalassemia major are born in India. Of these, 200 are added every year from Delhi alone. Since thalassemia carriers are clinically normal and healthy, they are ignorant of their carrier status. They only learn of it, if their blood is tested, or they have a child affected with thalassemia major, in which event, the spouse is also a carrier.

Patients of thalassemia major require repeated blood transfusions throughout their life for survival. These children also need injections/drugs in order to remove excess iron from the body. The cost of therapy is about Rs $150,000-200,000$ per child per year. Risk of transfusion-transmitted diseases, loss of time, energy, and expenditure, coupled with apprehension of shortened life span causes a lot of emotional as well as financial stress to the whole family. The only definite treatment available for cure of thalassemia major is bone marrow transplant which is available at selected places only, and costs about Rs $800,000-1000,000$ which is unaffordable by most of the affected families. It is also limited by the availability of HLA-matched bone marrow donors.

If both the parents have thalassemia trait, as per Mendelian law of inheritance, there is $25 \%$ probability of having a child with thalassemia major, $25 \%$ chance of having a normal child, and $50 \%$ chance of a child with thalassemia trait. The development of methods to diagnose thalassemic major in utero, allows the obstetrician to give definite answers rather than giving statistical probabilities. With the help of thalassemia screening during the antenatal period followed by prenatal diagnosis, "couples at-risk" can avoid having affected children without remaining childless and are spared from months of anxiety awaiting the outcome of pregnancy $[1,2]$.

Cyprus, Sardinia, Italy and Greece have been able to control thalassemia with their extensive screening programme at various levels along with antenatal diagnosis. Some of the countries have made premarital screening for thalassemia mandatory.

If screening is initiated in the premarital age group, before conception and in early pregnancy, there is no reason why we cannot wipe off the trauma of thalassemia major from India. This severe disorder can be prevented by education, generating public awareness, screening, premarriage counseling, and prenatal diagnosis. Screening for thalassemia carrier status can be done with NESTROFT, red cell indices, and HPLC analysis. Since HPLC analysis is expensive and the equipment is not widely available, it is not suitable for mass-screening programs in resource-poor countries. The present study was done to evaluate the sensitivity and specificity of NESTROFT and red cell indices in thalassemia-trait screening in antenatal women and their feasibility for use in mass-screening programs.

\section{Materials and Methods}

The study was conducted in the Department of Obstetrics \& Gynecology of Hindu Rao Hospital, New Delhi, over the period of 2 years from year 2008 to 2010 , after obtaining ethical clearance from the institutional review committee. One thousand antenatal patients with gestational age less than 20 weeks were studied. Informed consent was obtained prior to the enrollment of the subjects. Detailed history was taken and careful physical examination was done at the first antenatal visit. NESTROFT, CBC, and HPLC were analyzed in all the patients. Husbands of women who were confirmed to be carriers on HPLC analysis were screened, to identify the "high-risk couples". Prenatal genetic testing and counseling were advised to the couple, where both husband and wife were thalassemiatrait positive. Such patients were referred to other centers for prenatal diagnosis by CVS or cordocentesis, whichever was applicable.

\section{Results}

Maximum number of patients were from Delhi (35.4\%), followed by UP (24\%), Haryana (12.2\%), Punjab $(11.2 \%)$, and Bihar $(10.4 \%)$. Thalassemia trait was detected in $2.9 \%$ of women from Delhi, in $1.7 \%$ women from UP, in $1 \%$ of women from Bihar, $1.4 \%$ women from Haryana, $0.6 \%$ from Punjab, and $0.03 \%$ in those from other states.

Maximum women $(53.1 \%)$ were screened at the gestational age of 8-12 weeks, $36.8 \%$ at $12-16$ weeks, $5.9 \%$ at 16-20 weeks of gestation, and $4.2 \%$ were screened at gestational age of less than 8 weeks.

The sensitivity, specificity, positive predictive value and negative predictive value of NESTROFT, RBC indices taken together $(\mathrm{MCV}<80 \mathrm{fL}, \mathrm{MCH}<27 \mathrm{pg}$, and $\mathrm{RBC}$ count $>5$ million/L) and individual parameters like $\mathrm{MCV}$, 
Table 1 Comparison of sensitivity, specificity, positive predictive value, and negative predictive value of NESTROFT and other RBC indices

\begin{tabular}{lllllr}
\hline Tests & NESTROFT (\%) & $\begin{array}{l}\text { RBC indices (MCV, MCH, } \\
\text { and RBC count) }(\%)\end{array}$ & MCV (\%) & MCH (\%) & RBC count (\%) \\
\hline Sensitivity & 78.48 & 73.42 & 73.42 & 60.76 & 32.91 \\
Specificity & 94.14 & 70.25 & 85.88 & 74.16 & 93.81 \\
Positive predictive value & 53.45 & 17.47 & 30.85 & 16.78 & 31.32 \\
Negative predictive value & 98.08 & 96.86 & 97.41 & 95.66 & 94.22 \\
\hline
\end{tabular}

$\mathrm{MCH}$, and RBC count is shown in Table 1. NESTROFT was found to have maximum sensitivity and RBC count was found to have maximum specificity, closely followed by NESTROFT. Positive predictive value and negative predictive value was again highest for NESTROFT.

It was observed (Table 2) that mean $\mathrm{Hb}$ for (79) cases of $\beta$-thalassemia trait (BTT) was $11 \pm 1.80 \mathrm{~g} / \mathrm{dL}$ and differed significantly from non-BTT cases $(11.5 \pm 1.68 \mathrm{~g} / \mathrm{dL}$, $\mathrm{p}<0.05$ ).

The mean RBC count (Table 3) for BTT (4.60 \pm 0.72 million/L) differed significantly from that in the nonBTT cases $(4.04 \pm 0.57$ million/L, $\mathrm{p}<0.05)$.

The mean MCV (Table 4) for women with BTT (75.96 \pm $11.39 \mathrm{fL}$ ) differed significantly from women without BTT $(88.61 \pm 8.21, \mathrm{p}<0.05)$.

The mean MCH (Table 5) for women with BTT (24.83 \pm $5.07 \mathrm{pg}$ ) differed significantly from that in women without BTT cases $(28.77 \pm 3.39 \mathrm{pg}, \mathrm{p}<0.05)$.

Table 6 shows that hemoglobin, MCV, MCH, MCHC and PCV in the BTT cases had lower values than in nonBTT cases, but higher values of RBC count.

The mode of delivery was vaginal in $90.32 \%$ of BTT cases and $88.74 \%$ of non-BTT cases, whereas, LSCS was done in $9.68 \%$ of BTT cases and $11.26 \%$ of non-BTT cases. There was no statistically significant difference in the modes of delivery between BTT and non-BTT cases $(\mathrm{p}>0.05)$.

Birth weight in babies of mothers with BTT did not differ significantly from that in babies of non-BTT mothers. There was also no difference in the number of preterm deliveries in the two groups ( $\mathrm{p}>0.05)$.

Table 2 Comparison of hemoglobin $(\mathrm{Hb})$ values in women with $\beta$ thalassemia trait (BTT) and women without BTT

\begin{tabular}{lllllc}
\hline Hb level $(\mathrm{g} / \mathrm{dL})$ & \multicolumn{2}{l}{$\mathrm{BTT}$ cases $(\mathrm{n}=79)$} & & \multicolumn{2}{l}{ Non-BTT cases $(\mathrm{n}=921)$} \\
\cline { 2 - 3 } \cline { 5 - 6 } & $\mathrm{N}$ & Percent $(\%)$ & & $\mathrm{N}$ & Percent $(\%)$ \\
\hline $6-8$ & 3 & 3.79 & & 28 & 3.04 \\
$8-10$ & 25 & 31.6 & & 132 & 14.33 \\
$10-12$ & 32 & 40.50 & & 398 & 43.21 \\
More than 12 & 19 & 24 & & 363 & 39.41 \\
Mean $\mathrm{Hb}$ & $11 \mathrm{~g} / \mathrm{dL}$ & & $11.5 \mathrm{~g} / \mathrm{dL}$ & \\
\hline
\end{tabular}

The husbands of 79 women who were diagnosed as thalassemia-trait carriers with $\mathrm{HbA} 2>3.5 \%$ were also analyzed by HPLC. Only two were diagnosed to have thalassemia trait. CVS was done in these two women. In one of them, the fetus was diagnosed to have thalassemia trait, and the mother continued the pregnancy and the baby delivered at term. In the other case, the fetus was diagnosed to have thalassemia major and the couple opted for medical termination of pregnancy. Overall, we could prevent the birth of one baby with thalassemia major.

\section{Discussion}

In India, $3.3 \%$ of population [3] is carrier of thalassemia and 6000-8000 children are born every year with thalassemia major [4]. The prevalence of thalassemia trait varies from less than $2 \%$ to over $7 \%$ in Delhi in different ethnic groups. In the present study, $\beta$-thalassemia trait was detected in $7.9 \%$ of the cases. The state wise prevalence of BTT was $2.9 \%$ in cases originally belonging to Delhi, $1.7 \%$ in cases from UP, $1 \%$ in cases from Bihar, whereas 0.6 and $1.4 \%$ in cases from Punjab and Haryana, respectively. The carrier rate of BTT varies from $1 \%$ to $17 \%$ in India with an average of 3\%-4\% [5]. In a study by Bhukhanvala et al. [6], in Gujarat, the prevalence of BTT was $3.38 \%$. In Madhya Pradesh, Baxi et al. [7] reported the rate of BTT as $2.7 \%$ among 1006 pregnant women.

In the present study, the sensitivity and specificity of NESTROFT was found to be $78.48 \%$ and $94.14 \%$, respectively. The positive and negative predictive value of NESTROFT was noted to be $53.45 \%$ and $98.08 \%$, respectively. This was better than the red cell indices taken alone (see Tables 1, 2, 3, 4, 5, 6). Mehta and Gandhi [8], in a study of antenatal women, reported the negative predictive value of NESTROFT as $100 \%$ and of MCV as $98.2 \%$. The predictive value of a positive test in yielding the diagnosis of BTT was higher with NESTROFT $(59.1 \%)$ than with MCV $(28.1 \%)$. In this study of screening for BTT in antenatal women, NESTROFT was more efficient $(89.5 \%)$ than MCV $(49.5 \%)$.

Manglani et al. [9] screened 2525 subjects in the general population and reported that NESTROFT provided a 
Table 3 Comparison of RBC counts in BTT and non-BTT cases of study group

\begin{tabular}{|c|c|c|c|c|}
\hline \multirow[t]{2}{*}{ RBC count (million/L) } & \multicolumn{2}{|c|}{ BTT cases $(\mathrm{n}=79)$} & \multicolumn{2}{|c|}{ Non-BTT cases $(\mathrm{n}=921)$} \\
\hline & $\mathrm{N}$ & Percent $(\%)$ & $\mathrm{N}$ & Percent $(\%)$ \\
\hline Less than 5 million & 53 & 67.08 & 864 & 93.81 \\
\hline More than 5 million & 26 & 32.91 & 57 & 6.19 \\
\hline Mean RBC count & \multicolumn{2}{|c|}{4.60 million/L } & \multicolumn{2}{|c|}{4.04 million/L } \\
\hline
\end{tabular}

Table 4 Comparison of MCV values in women with BTT and without BTT

\begin{tabular}{llllll}
\hline MCV (fL) & \multicolumn{2}{l}{ BTT cases $(\mathrm{n}=79)$} & & \multicolumn{2}{l}{ Non-BTT cases $(\mathrm{n}=921)$} \\
\cline { 2 - 3 } \cline { 5 - 6 } \cline { 5 - 6 } & $\mathrm{N}$ & Percent $(\%)$ & & $\mathrm{N}$ & Percent $(\%)$ \\
\hline Less than 80 & 58 & 73.42 & & 130 & 14.12 \\
$80-96$ & 20 & 25.32 & & 651 & 70.68 \\
More than 96 & 1 & 1.26 & & 140 & 15.20 \\
Mean MCV & $75.94 \mathrm{fL}$ & & $88.61 \mathrm{fL}$ & \\
\hline
\end{tabular}

Table 5 Comparison of values of $\mathrm{MCH}$ in BTT and non-BTT cases

\begin{tabular}{llllll}
\hline MCH $(\mathrm{pg})$ & \multicolumn{2}{l}{ BTT cases $(\mathrm{n}=79)$} & & \multicolumn{2}{l}{ Non-BTT cases $(\mathrm{n}=921)$} \\
\cline { 2 - 3 } \cline { 5 - 6 } \cline { 5 - 6 } & $\mathrm{N}$ & Percent $(\%)$ & & $\mathrm{N}$ & Percent $(\%)$ \\
\hline Less than 27 & 48 & 60.76 & & 238 & 25.84 \\
$27-31$ & 21 & 26.58 & & 450 & 48.86 \\
More than 31 & 10 & 12.66 & & 140 & 15.20 \\
Mean $\mathrm{MCH}$ & $24.83 \mathrm{pg}$ & & $28.77 \mathrm{pg}$ & \\
\hline
\end{tabular}

sensitivity of $94.4 \%$ as a single parameter. The sensitivity of MCV ( $<80 \mathrm{fL}$ ) was $93.7 \%$. When combined with MCV ( $<80 \mathrm{fL}$ ), NESTROFT provided $100 \%$ sensitivity. However, the combination requires and additional red cell indices study.

Gomber et al. [10], analyzed pediatric patients at a tertiary care hospital, and observed that NESTROFT had a higher sensitivity and specificity than direct red cell indices for screening of thalassemia. In this study of 253 subjects, NESTROFT had a sensitivity and specificity of $85.71 \%$ and $81.7 \%$, respectively while sensitivity and specificity for MCV ( $<70 \mathrm{fL}$ ) was $57.1 \%$ and $81 \%$, respectively. The sensitivity and specificity of RBC count ( $<4.5$ million) was $71.4 \%$ and $55.5 \%$, respectively. The study concluded that NESTROFT is an inexpensive and easily reproducible test for population screening of $\beta$-thalassemia trait.

Fleming [11] studied fetal outcome in thalassemia minor, and reported that none of the thalassemia-minor patients had low birth weight babies or had complications with delivery. Similar results were observed in the present study. Alger et al. [12] observed no difference in maternal age, parity, gravidity, and the number of previous abortions, still births, and neonatal deaths between women who were carriers of $\alpha$-thalassemia or $\beta$-thalassemia as compared to those of the control population. There was no difference in mode of delivery, placental weight, fetal and placental ratio, or gestational age between $\alpha$-thalassemia and $\beta$-thalassemia, and between thalassemic and control population. The results in the present study were similar to their study.

Pakes et al. [13] also observed no difference in the complications during pregnancy in cases with thalassemia minor as compared to control women. They found no evidence of increased fetal distress and perinatal death. The present study also showed similar results.

Since India is a country with cost constraints, it will not be economical to do HPLC analysis for mass screening of $\beta$-thalassemia trait. It is thus recommended that either NESTROFT or red cell indices, or combination of the two tests be used for mass-screening program. However, MCV determination by manual RBC count is often unreliable thus necessitating an automated particle counter. Though combination of these two tests would be ideal, it would require automated cell counters and technical staff in peripheral areas.
Table 6 Comparison of mean hematological values between BTT and non-BTT cases

\begin{tabular}{llc}
\hline Hematological values & $\begin{array}{l}\text { Mean value in } \\
\text { BTT cases }\end{array}$ & $\begin{array}{l}\text { Mean value in } \\
\text { non-BTT cases }\end{array}$ \\
\hline $\mathrm{Hb}(\mathrm{g} / \mathrm{dL})$ & 11 & 11.5 \\
$\mathrm{RBC}$ count (million/L) & 4.60 & 4.04 \\
$\mathrm{MCV}(\mathrm{fL})$ & 75.94 & 88.61 \\
$\mathrm{MCH}(\mathrm{pg})$ & 24.83 & 28.77 \\
$\mathrm{MCHC}(\mathrm{g} / \mathrm{dL})$ & 31.5 & 32.16 \\
$\mathrm{PCV}(\%)$ & 34.79 & 35.25 \\
$\mathrm{HbA2}$ & 5.54 & 2.74 \\
\hline
\end{tabular}




\section{Conclusion}

Though HPLC analysis is the gold standard for diagnosis of $\beta$-thalassemia trait, it is not feasible for mass screening in developing countries. NESTROFT, in combination with other hematological parameters, detected majority of BTT cases, and hence combination of the two tests is ideal for mass-screening programme. However, MCV determination by manual RBC count is often unreliable thus necessitating an automated particle counter. NESTROFT is a reliable screening test for detection of $\beta$-thalassemia trait in the Indian population because it is sensitive, cost effective, rapid and can be used for field studies as it does not require sophisticated equipment or technical expertise, and can be done from capillary blood obtained from finger prick.

Conflicts of interest None.

\section{References}

1. Colah RB, Gorakshakar A, Surve R, et al. Feasibility of antenatal screening of $\beta$-thalassemia in Mumbai, India. Acta Heamatol. 2001;105:252.

2. Colah R, Surve R, Wadia M, et al. Carrier screening for $\beta$-thalassemia during pregnancy in India: a 7 year evaluation. Genet Test. 2008;12:181-6.
3. Verma IC, Choudhary VP, Jain PK. Prevention of thalassemia: a necessity in india. Indian J Pediatr. 1992;59:649-54.

4. Varawalla NY, Old JM, Sarkar R, et al. The spectrum of Betathalassemia mutations on the Indian subcontinent: the basis for prenatal diagnosis. Br J Hematol. 1991;78:242-7.

5. Modell B, Petrou M. The Problem of the hemoglobinopathies in India. Ind J Hematol. 1983;1:5-16.

6. Bhukhanvala DS, Sorathiya SM, Sawant P, et al. Antenatal screening for identification of couples for prenatal diagnosis of severe hemoglobinopathies in Surat, South Gujrat. J Obstet Gynaecol India. 2013;63(2):123-7.

7. Baxi A, Manila Kaushal, Kadhi P, et al. Carrier screening for $\beta$ thalassemia in pregnant Indian women. Experience at a single centre in Madhya Pradesh. Indian J Hematol Blood Transfus. 2013;29(2):71-4.

8. Mehta BC, Gandhi S. Screening for beta thalassemia trait with naked eye single tube red cell osmotic fragility test in hematology clinics. Ind J Med Sci. 2002;56:537-44.

9. Manglani M, Lokeshwar MR, Vani VG, et al. 'NESTROFT': an effective screening test for beta thalassemia trait. Indian Pediatr. 1997;34:702-7.

10. Gomber S, Sanjeev, Madan N. Validity of NESTROFT in screening and diagnosis of $\beta$-thalassemia trait. J Trop Pediatr. 1997;42:363-6.

11. Fleming AF. Maternal anemia and fetal outcome in pregnancies complicated by thalassemia minor and stomatocytosis. Am J Obstet Gynecol. 1973;116:309.

12. Alger LS, Globus MS, Laros PK. Thalassemia and pregnancy. Am J Obstet Gynecol. 1979;134:662-73.

13. Pakes JB, Cooperberg AA, Gelfernd MM. Studies on beta thalassemia trait in pregnancy. Am J Obstet Gynecol. 1970;108: $1217-23$. 